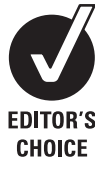

Discipline of Public Health, The University of Adelaide, Adelaide, Australia; ${ }^{2}$ European Observatory on Health Systems and Policies, Brussels, Belgium

Correspondence to:

Professor C Gericke, Chair in

Public Health Policy, Director

Centre for Health Services

Research, The University of

Adelaide, 10 Pulteney Street,

MDP 207, Adelaide SA 5005,

Australia; christian.gericke@

adelaide.edu.au

Received 13 August 2008

Revised 14 December 2008

Accepted 19 December 2008

\title{
Ethical issues in funding research and development of drugs for neglected tropical diseases
}

\author{
L Oprea, ${ }^{1}$ A Braunack-Mayer, ${ }^{1}$ C A Gericke ${ }^{1,2}$
}

\section{ABSTRACT}

Neglected and tropical diseases, pervasive in developing countries, are important contributors to global health inequalities. They remain largely untreated due to lack of effective and affordable treatments. Resource-poor countries cannot afford to develop the public health interventions needed to control neglected diseases. In addition, neglected diseases do not represent an attractive market for pharmaceutical industry. Although a number of international commitments, stated in the Millennium Development Goals, have been made to avert the risk of communicable diseases, tropical diseases still remain neglected due to delays in international assistance. This delay can be explained by the form international cooperation has generally taken, which is limited to promoting countries' national interests, rather than social justice at a global level. This restricts the international responsibility for global inequalities in health to a humanitarian assistance.

We propose an alternative view, arguing that expanding the scope of international cooperation by promoting shared health and economic value at a global level will create new opportunities for innovative, effective and affordable interventions worldwide. It will also promote neglected diseases as a global research priority. We build our argument on a proposal to replace the patenting system that currently regulates pharmaceutical research with a global fund to reward this research based on actual decreases in morbidity and mortality at a global level. We argue that this approach is beneficent because it will decrease global health inequalities and promote social justice worldwide.

Neglected diseases-communicable infectious and parasitic infections other than malaria, tuberculosis and HIV-are pervasive in developing countries, and they predominantly affect the worst-off in those societies. ${ }^{1}$ They are responsible for significant inequalities between rich and poor countries, ${ }^{2-5}$ and remain largely untreated due to a lack of safe, effective and affordable treatments. ${ }^{6}$ Resource-poor countries can not afford to develop the public health interventions required to improve the health of their populations. ${ }^{7}$ Additionally, the incentives that exist at the international level to promote research and development into rare and neglected diseases have little impact on these diseases, because the treatment of such diseases does not represent an attractive market for the pharmaceutical industry. ${ }^{8} 9$

In 2000, a number of international commitments, stated in the United Nations Millennium Development Goals, and international pledges of annual public contributions of $0.7 \%$ of the gross domestic product (GDP) of Organisation for
Economic Cooperation and Development (OECD) countries have been made to avert the risk of communicable diseases in the developing world. ${ }^{10}$ The World Health Organization (WHO) has developed a comprehensive plan to deal with neglected diseases. ${ }^{1}$ However, after eight years with only $0.3 \%$ of the GDP of OECD countries spent to reach Millenium Developing Goals, ${ }^{11}$ tropical diseases still remain neglected, deepening the global inequalities in health. ${ }^{3}$

This delay can be explained in part by the form that international cooperation has generally taken, which has been mainly limited to promoting the national interests of countries. ${ }^{12}$ This approach tends to balance national interests of developed countries against those of resource-poor countries, restricting international cooperation to humanitarian assistance to a range of vulnerable groups whose needs are not met by the market economy and limiting the responsibility of OECD countries for reducing global health inequalities. ${ }^{12} 13$

In this paper we propose an alternative view, arguing that expanding the scope of international cooperation by promoting shared health and economic value as a common good at a global level will create new opportunities for innovative, effective and affordable interventions worldwide. It will also promote neglected diseases as a global research priority. We build our argument on an expanded version of Thomas Pogge's proposal to create a global fund in parallel with a patenting system to reward pharmaceutical research at a global level based on actual health gains measured in terms of decreased morbidity and mortality at a community level. ${ }^{414}$ We take Thomas Pogge's proposal one step further by suggesting that the WHO Global Plan to Combat Neglected Diseases ${ }^{1}$ should include collaboration with international financial organisations and national governments to replace the current patenting system by a global fund to reward pharmaceutical research on the global scale. In our view, the creation of parallel funding systems will not be able to overcome the market failure of the global pharmaceutical market.

We argue that this approach promotes: (a) beneficence, as it will promote research on neglected diseases as a global priority because it focuses research interests on the worst-off in all societies; and (b) social justice at a global level. In the following discussion we will analyse the expected impact of the proposed mechanism from the perspectives of beneficence and social justice respectively. Finally, we draw a number of conclusions for international health policy and practice based on this analysis. 


\section{BENEFICENCE}

Changing the patenting system to a global fund which rewards pharmaceutical research based on actual health gains measured in terms of decreased morbidity and mortality produced by newly developed drugs and other health technologies is beneficent. Such a fund would expand the opportunities for innovative, effective and affordable drugs in any country. In addition, it could decrease the inequalities in health between global poor and rich because it can focus research interests on resource-poor countries and on the worst-off in any given society. Thus, it has the potential to support the Global Plan to Combat Neglected and Tropical Diseases by promoting neglected diseases as a research priority at a global level.

The current patenting system, under which global pharmaceutical research is developed, subordinates global and national health and economic needs to the commercial interests of pharmaceutical industry. The patenting system attempts to promote pharmaceutical research by rewarding pharmaceutical companies with market exclusivity for their products. ${ }^{15}$ Such a system does not provide enough market incentives to develop innovative, effective and affordable medicines or health technologies because it focuses the market competition between pharmaceutical companies on bargaining for global commercial power, rather than on adding societal value. It encourages pharmaceutical companies to acquire global monopolies for their products, through a complex international system that allows the registration of patents in different jurisdictions around the world. ${ }^{4}$ There is evidence that market monopolies undermine businesses' potential to find innovative, effective and affordable products and produce marginal benefits for consumers. ${ }^{16}$

In this way, the current patenting system impedes both health gains and economic development in both developed and developing nations. It clearly diverts pharmaceutical research from the health needs of developing countries whose economies cannot secure sufficient financial returns to recoup companies' investments in pharmaceutical research. ${ }^{8}$ At the moment, the incentives for pharmaceutical research are best related to the methods that are used to assess health technologies' costeffectiveness. Health technology assessment usually involves an evaluation of the incremental cost-effectiveness of the new therapy compared to alternative treatments for the disease in question. ${ }^{17}$ Developing "me-too" medicines that produce small health improvements in a large number of people thus offers better financial rewards for pharmaceutical companies than developing innovative medicines that produce major improvements in a smaller number of people. ${ }^{18}$

Through these pathways the patenting system discourages responsibility on the part of pharmaceutical companies for the production of innovative, effective and affordable drugs. Not surprisingly, this system has led to only 16 new drugs for neglected diseases out of the 1393 chemical entities marketed between 1975 and 1999, and to only 21 drugs included in the WHO list of essential medicines. ${ }^{6}$ The current patenting system fosters the development of expensive medicines with a low index of innovation. The real markets for pharmaceutical companies are healthcare systems worldwide. In high income countries, healthcare (including the provision of pharmaceuticals) is predominantly funded from public sources, either general taxation or social health insurance. ${ }^{19}$ In developing countries the share of national public financing is much smaller and most of the burden of purchasing medicines falls on households. However, in some low income countries the share of international public financing can be quite substantial. Since
1970, the average share of GDP for pharmaceuticals in most OECD countries has increased $1.5 \%$ more per year than their GDP growth ${ }^{20}$ whereas the drug spending growth rate between 1995-9 has been more than twice that of overall healthcare spending. ${ }^{21}$ It is highly unlikely that the health gains achieved through this higher pharmaceutical spending justify the costs which means that the current incentive system operating in the pharmaceutical market is inefficient. The opportunity cost to societies in both developed and developing countries in terms of benefits foregone is substantial.

Thomas Pogge ${ }^{414}$ has proposed a reform plan to solve these societal failures. It consists of three components that aim to promote community health in both developed and developing countries. First, the plan allows any new essential medicine to be provided as a global public good that can be used free of charge by any pharmaceutical company. This eliminates the market's failure to drive prices down due to lack of competition imposed by the actual patenting system. Second, inventor companies are to be entitled to a multiyear patent on any essential medicines they invent but during the life of the patent they would be rewarded from public funds proportional to the impact of their medicines on the global burden of diseases. Under this component, companies would freely opt to register their medicines under the proposed scheme or under the actual patenting system. This freedom of choice on the companies' part would allow the preservation of nonessential medicinesthose medicines that address medical conditions which add little to the global burden of diseases such as drugs for impotence or acne-for which people in affluent nations would be willing to pay. Third, because this plan might cost between US $\$ 45-90$ billion annually on a global scale, there is a need to develop a fair, feasible and realistic allocation of these costs, as well as convincing arguments in support of this allocation.

Although we agree with the general principle of this proposal, we argue that it would better reach its scope to improve global health if it promoted a unitary system to reward new pharmaceuticals based on their actual impact on health. By doing so it would create new opportunities for the development of innovative, effective and affordable therapies. It would reorient market competition between pharmaceutical companies away from bargaining for commercial power and towards adding value for the global community. By removing market monopolies for pharmaceutical products, the new mechanism would promote open markets and, by rewarding decreases in morbidity and mortality, it would focus market competition on improving community health. Limiting this mechanism to essential medicines for resource-poor countries and allowing the current patenting system to continue for all other medicines would maintain current global market monopolies and the inherent market failure. This would maintain incentives for pharmaceutical companies to develop expensive drugs with a low index of innovation and which especially target developed markets. This is so because the costs of innovation are higher ${ }^{18}$ and, in the absence of competition, pharmaceutical companies will select the easiest path precluding even the intended development of essential medicines. In addition, the coexistence of both systems would put an extra financial burden on developed countries, which would have to bear both the costs of developing essential medicines and those incurred by market monopolies.

In our view, combining market and community incentives for all new pharmaceuticals has a higher potential to promote the development of innovative and affordable medicines. Our approach would promote shared health and economic value 
for all countries. The new fund would shift the focus of pharmaceutical research from the health needs of developed countries, where pharmaceutical industry is located, ${ }^{6}$ to a global level. This approach would better meet the health and economic needs of all countries. In rewarding pharmaceutical research for actual health gains, it would focus the business interests of pharmaceutical companies on resource-poor settings where there is the highest scope for health improvement. ${ }^{21}$ In this way, it could incorporate the health needs of resource-poor countries into global research agendas, while simultaneously continuing to support the research needs of developed countries, such as treatment for the epidemic of chronic, non-communicable diseases. $^{22} 23$

Focusing business interests on resource-poor settings would also prompt the pharmaceutical industry to find the most affordable therapeutic solutions to decrease morbidity and mortality in these countries. For example, they could cooperate with smaller pharmaceutical companies to produce generic drugs that will be more accessible for people living in resourcepoor areas. ${ }^{4}$ In turn, open markets would allow OECD countries access to effective and affordable therapies developed in poorer countries and this would decrease their healthcare costs.

Pogge $^{14}$ has argued that, in the absence of the current patenting system, medicines for diseases such as impotence or acne may disappear because their treatment can add little to the reduction in the global burden of diseases. In our view, medicines for these diseases will not disappear because a global approach would increase the number of people with these medical conditions. In addition, collaborative approaches such as those already mentioned may increase the capacity of pharmaceutical companies to make these medicines viable by increasing their biological effectiveness and by marketing them at affordable prices to reach patients from all social groups.

The fact that this approach would reward innovation means that more expensive drugs with a very low index of innovation and which produce little improvement in health status may disappear because this approach would give pharmaceutical manufacturers an incentive to develop the most effective therapeutic solutions. A fund that rewards real gains in community health, measured through decreases in morbidity and mortality, would expand the scope for innovation in pharmaceutical products. It would promote the health needs of individuals in all social groups while, at the same time, offering the greatest benefits for the worst-off social groups.

This redistribution effect is desirable from a beneficence perspective because it has the potential to promote shared responsibility on the part of countries, communities, research organisations and pharmaceutical companies for people's health. It would also support collaborative and multidisciplinary research focused on finding creative and comprehensive biological, culturally sensitive and affordable solutions to increase the access of different social groups in different communities around the world to newly developed medicines.

Through all these pathways a fund that rewards global pharmaceutical research would focus research interests on resource-poor countries and on the worst-off social groups globally. In our view it would highlight neglected diseases as a global research priority in several ways. It would make the required funds for neglected diseases available through direct contributions from all countries, instead of mainly OECD countries. In addition, it would focus research interests on neglected diseases because eradicating these diseases would be associated with significant health gains at a community level, in part through minimising the impact of co-morbidities such as anaemia, chronic diarrhoea, malnutrition, infertility and blindness, ${ }^{24}{ }^{25}$ and decreasing susceptibility to tuberculosis, malaria and HIV/AIDS. ${ }^{26-29}$

Our approach would also support the private public partnerships (PPP) promoted by the WHO Global Plan to Combat Neglected and Tropical Diseases as a solution to promote research for neglected diseases. ${ }^{1}$ It would make these partnerships central to sustainable business interests in the long run. A global fund would also support participation in other public or commercial partnerships to make drugs for neglected diseases affordable. ${ }^{4}$

Thus, our approach meets the requirements of beneficence, promoting multiple opportunities for innovative, effective and affordable drugs at a global level and increasing the access to these medicines of individuals across the whole social spectrum.

\section{SOCIAL JUSTICE}

A fund to reward global pharmaceutical research can promote social justice because it supports human rights in all countries. We are using a human rights framework in this section because it provides the main political tool to assess policy from an ethical perspective at the international level. ${ }^{30}$ First, we argue that this approach removes conflicts between the collective health and economic rights of different countries. Thus it promotes health and economic freedom and avoids discrimination. Second, we explore the relation between individual rights, such as the right to health and property rights, and argue that this approach removes the conflicts between rights.

A global fund can promote collective health and economic rights in all countries, because it reconfigures international cooperation as global social justice, rather than only as humanitarian assistance to vulnerable countries. In our view, an emphasis on promoting shared economic and health value provides better political arguments for developing pharmaceutical research as a global public good rather than an emphasis on national interests. A focus on national interests requires balancing the national interests of developed countries and developing countries ${ }^{13}$ towards promoting pharmaceutical research as a global public good because its costs will be supported by developed countries in the first instance.

Ex ante and ex post arguments underlining the national interest of developed countries to support global pharmaceutical research have been made. ${ }^{14}{ }^{31}$ Ex ante, it is in the interests of developed countries to control infectious disease in the developing world to prevent epidemics in their own countries in the context of increased global mobility. Ex post, it is legitimate to compensate developing countries for deficits in health and economic rights brought upon them through unjust actions in and by developed nations. ${ }^{31}$ For instance, the brain drain from developing to developed countries resulting from specific policies in developed countries to recruit much sought after professionals such as doctors and nurses from developing countries has created a rights-deficit in developing nations. In our view, these arguments, although they might be correct, are not enough to justify the market failure observed in global pharmaceutical research. First, both ex ante and ex post arguments cannot inform policy with respect to the amount of resource allocation. For instance, it may be difficult to assess the retrospective harm produced by developed nations in some countries to quantify the amount of actual allocations that may be needed as compensation. Second, because this balance of interests between countries is litigious in nature it may undermine the collaborative approaches needed by this mechanism to reach its full benefits. 
By contrast, a focus on shared economic and health values focuses on the points of intersection between countries' national interests promoting ex ante relational justice. It emphasises that solidarity between countries could expand their health and economic freedom. First, this fund would avoid the current division of research and development in two separate markets: one lucrative and the other of no interest to companies, with the inherent health and economic discrimination against people living in low income countries.

Second, the proposed mechanism has the potential to be Pareto-efficient ${ }^{32}$ - there would only be winners and no losers on the consumer side-because it establishes an instrumental relationship between the economic and health opportunities of different countries. For instance, by promoting health in resource-poor countries our approach would expand the opportunities for effective and affordable therapies in OECD countries. This would focus research on areas with the greatest scope for health and economic improvement and, through this, lead to reductions in the global gradient in health. It would also avoid health and economic discrimination because it does not take anything away from better-off countries. Thus it would have the potential to increase the solidarity between countries, prompting them to nourish their relationships to expand each others' opportunities and indirectly to maximise their interests.

This shift from promoting national interests to promoting shared value is significant for research ethics in resource-poor settings. It would decrease the tensions between pharmaceutical research interests and access to outcomes of research for lowresource communities which participate in research. Although a recent guideline $e^{33}$ has stressed the importance of fair benefits for participating communities in developing countries, several authors have emphasised the difficulties to find adequate tools to assess the level, allocation and priority setting for funding development. ${ }^{8}$ This approach does not solve these distributive problems but it can help to decrease the public burden by making these benefits accessible, increasing responsibility on the part of pharmaceutical industry to ensure that communities have access to research outcomes.

Our approach would also invert the relationship between the collective right to health and the commercial rights of pharmaceutical companies. Currently, market exclusivity subordinates community health needs to the property rights of shareholders of pharmaceutical companies. Our approach would remove this tension by subordinating the commercial rights of pharmaceutical companies, which are institutional rights, to community health needs. This approach is justified because the market economy is a public good and its main ethical justification at a societal level is to promote shared economic value. ${ }^{16}$ Institutional rights should promote shared value at a collective level, rather than the property rights of certain interest groups. This mechanism would promote individual rights to health by creating multiple opportunities for good health for all social groups without making trade-offs between the health interests of different social groups. In turn, society would reward pharmaceutical businesses for their impact on community health. Implicitly it would also promote the property rights of the shareholders of pharmaceutical companies.

Through all these pathways our approach expands human freedom and avoids social discrimination. It expands opportunities for good health for all people regardless of their social stratum or age group and increases access to new, effective, innovative and affordable therapeutic solutions. In addition, because it removes market exclusivity, our approach expands business opportunities for pharmaceutical companies.

\section{CONCLUSIONS}

We have argued that an emphasis on international cooperation devoted to promoting countries' shared health and economic value can support research for neglected diseases as a global priority. We have built our argument on Thomas Pogge's proposal ${ }^{4}$ to develop a global fund to reward global pharmaceutical research based on community health gains measured in terms of decreased morbidity and mortality. We have argued that this approach is beneficent because it has the potential to improve global health through rewarding the development of innovative, effective and affordable therapies in all countries. At the same time, this approach offers the greatest benefits to the worst-off social groups within countries and decreases global inequalities in health.

We have also argued that such a global fund can promote social justice at the global level by shifting international relations away from an emphasis on national interests and toward shared economic and health values via increased solidarity between countries. It focuses on the points of intersection between countries' health and economic interests, instead of on conflicts between national interests. Thus it has the potential to promote solidarity between countries to decrease global health inequalities. At the individual level this approach can both increase human freedom and avoid discrimination.

To some the proposed mechanism may sound utopian and it could be argued that it challenges the current reliance of governments and international organisations on market forces to regulate research and development of pharmaceuticals. However, in the existing system governments in many countries hold monopsony power in the pharmaceutical market and use it to extensively regulate pharmaceutical licensing, pricing and reimbursement. Adding a new policy instrument to redress market failure in driving innovative drug development is therefore not utopian but in the interest of both societies in developed countries and global society overall.

Competing interests: CAG has received research support, travel grants and speakers' honoraria from the pharmaceutical companies Janssen Cilag, Eli Lilly, Aventis, Novo Nordisk, Laboratoires Biocodex, Roche Diagnostics and GlaxoSmithKline.

Provenance and peer review: Not commissioned; externally peer reviewed.

\section{REFERENCES}

1. WHO/CDS/NTD. Global plan to combat neglected tropical diseases. Geneva: World Health Organization, 2007.

2. Benatar SR, Daar AS, Singer PA. Global health ethics: the rationale for mutual caring. Int Aff 2003;79:107-38.

3. Dodd R, Cassels A. Health, development and the Millennium Development Goals. Ann Trop Med Parasitol 2006;100:379-87.

4. Pogge T. Montreal statement on the human right to essential medicines. Camb 0 Healthc Ethics 2007;16:97-108.

5. Ruger JP. Ethics and governance of global health inequalities. J Epidemiol Community Health Nov 2006;60:998-1003.

6. Trouiller $\mathbf{P}$, Olliaro P, Torreele E, et al. Drug development for neglected diseases: a deficient market and a public-health policy failure. Lancet 2002;359:2188-94.

7. Ehrenberg JP, Ault SK. Neglected diseases of neglected populations: thinking to reshape the determinants of health in Latin America and the Caribbean. BMC Public Health 2005;5:119.

8. Gericke CA, Riesberg A, Busse R. Ethical issues in funding orphan drug research and development. J Med Ethics 2005;31:164-8.

9. Yamey G. Public sector must develop drugs for neglected diseases. BMJ 2002; 324:698.

10. United Nations. United Nations millennium declaration. New York: United Nations Department of Public Information, 2000. 
11. United Nations Economic and Social Commission for Asia and the Pacific/ UNDP/Asian Development Bank. The millennium development goals progress in Asia and the Pacific 2007. http://www.unescap.org/stat/mdg/MDG-ProgressReport2007.pdf (accessed 14 Feb 2009).

12. Daniels N. Equity and population health: toward a broader bioethics agenda. Hastings Cent Rep 2006;36:22-35.

13. Buchanan A, Decamp M. Responsibility for global health. Theor Med Bioeth 2006;27:95-114.

14. Pogge TW. Human rights and global health: a research program. Metaphilosophy 2005;36:182-209.

15. Johnston J, Wasunna AA. Patents, biomedical research, and treatments: examining concerns, canvassing solutions. Hastings Cent Rep 2007;37:\$1-36.

16. Porter ME, Kramer MR. Strategy and society: the link between competitive advantage and corporate social responsibility. Harv Bus Rev 2006;84:78-92.

17. Drummond MF, Wilson DA, Kanavos P, et al. Assessing the economic challenges posed by orphan drugs. Int J Technol Assess Health Care 2007;23:36-42.

18. Grabowski H. Patents, Innovation and Access to New Pharmaceuticals. J Int Economic Law 2002:5:849-60.

19. Busse R, Schreyögg J, Gericke CA. Health financing challenges in high income countries. HNP discussion paper series. World Bank, Washington, DC, 2007.

20. Almarsdottir AB, Traulsen JM. Cost-containment as part of pharmaceutical policy. Pharm World Sci 2005;27:144-8.

21. Anderson GF, Frogner BK, Johns RA, et al. Health care spending and use of information technology in OECD countries. Health Aff (Millwood) 2006;25:819-31.
22. Gwatkin DR, Guillot M, Heuveline P. The burden of disease among the global poor Lancet 1999;354:586-9.

23. Yach D, Hawkes C, Gould CL, et al. The global burden of chronic diseases: overcoming impediments to prevention and control. JAMA 2004;291:2616-22.

24. Riley LW, Ko Al, Unger A, et al. Slum health: diseases of neglected populations. BMC Int Health Hum Rights 2007;7:2.

25. WHO/CDS/NTD. Neglected tropical diseases Hidden successes emerging opportunities. 2006:40. http://whqlibdoc.who.int/hq/2006/WHO_CDS_NTD_2006. 2 eng.pdf (accessed 14 Feb 2009).

26. Vogel G. Infectious diseases. Tackling neglected diseases could offer more bang for the buck. Science 2006;311:592-3.

27. Druilhe $\mathbf{P}$, Tall A, Sokhna C. Worms can worsen malaria: towards a new means to roll back malaria? Trends Parasitol 2005;21:359-62.

28. Fincham JE, Markus MB, Adams VJ. Could control of soil-transmitted helminthic infection influence the HIV/AIDS pandemic. Acta Trop 2003:86:315-33.

29. Borkow G, Weisman Z, Leng Q, et al. Helminths, human immunodeficiency virus and tuberculosis. Scand J Infect Dis 2001;33:568-71.

30. Gostin L0. When terrorism threatens health: how far are limitations on personal and economic liberties justified? Fla Law Rev 2003;55:1105-70.

31. Daniels N. Equity and population health. Toward a broader bioethics agenda. Hastings Cent Rep 2006:36:22-35.

32. Pareto V. Manuale di economia politica. Milano: Libri Schiewiller, 1906.

33. WHO/CIOMS. International ethical guidelines for biomedical research involving human subjects. Geneva: CIOMS, 2002.

\section{Drug and Therapeutics Bulletin (DTB)}

\section{Your key source of unbiased, independent advice}

For over 45 years DTB has been an independent, indispensable part of evidence-based clinical practice. DTB offers healthcare professionals detailed assessment of, and practical advice on, individual medicines and other treatments, groups of treatment and the overall management of disease.

DTB is now also available online at http://dtb.bmj.com:

- browse or search all DTB content from the latest issue back to 1994

- email alerting, sophisticated searching, RSS feeds and full text links from cited references

- interactive services such as My Folders for quick access to articles that you have viewed previously and My Searches to save and re-use useful searches

- comment online on any DTB article

To subscribe, or for further information, please visit http://dtb.bmj.com 